\title{
气候变暖下大兴安岭落叶松径向生长对温度的响应
}

\author{
常永兴 陈振举* 张先亮 白学平赵学鹏 李俊霞 陆 旭
}

沈阳农业大学林学院树木年轮实验室, 沈阳 110866; 中国森林生态系统监测网络辽宁辽河平原森林生态系统定位研究站, 辽宁昌图 112500

摘 要 大兴安岭是我国气候变暖的敏感地区。为比较在升温过程中不同地区落叶松(Larix gmelinii)径向生长对温度的响应 差异, 在大兴安岭主脉南段、中段和北段进行树木年轮取样, 建立了各点年轮宽度年表, 根据年表第一主成分载荷系数分类 最终合成南部、中部和北部各区年轮指数。利用相关函数分析了落叶松径向生长与温度变化的关系, 结合主成分分析对比了 不同地区树木年轮宽度变化对温度的响应差异。结果表明: 落叶松径向生长对温度变化的响应呈现明显的南北差异(中部>北 部>南部); 南部年轮指数与上年 11 月到当年 4 月的平均温度显著相关, 中部年轮指数与上年生长季(6-8月)和当年3-10月的平 均温度显著负相关, 北部年轮指数与生长季前(4-5月)的平均温度极显著正相关。气候变暖背景下, 高温引起的区域暖干化使 土壤水分成为限制落叶松径向生长的主要因子, 土壤干旱程度加剧使落叶松生长对温度变化的响应增强。胸高断面积增量指 示的落叶松生产力经历了从响应低温胁迫到响应高温引起的水分胁迫的转变。未来几十年, 若温度持续升高, 大兴安岭地区 落叶松径向生长量将呈南部和中部降低、北部升高的趋势。

关键词 气候变暖; 大兴安岭; 落叶松; 年轮宽度; 径向生长; 温度变化; 敏感度

引用格式: 常永兴, 陈振举, 张先亮, 白学平, 赵学鹏, 李俊霞, 陆旭 (2017). 气候变暖下大兴安岭落叶松径向生长对温度的响应. 植物生态学报, 41, 279-289. doi: 10.17521/cjpe.2016.0222

\section{Responses of radial growth to temperature in Larix gmelinii of the Da Hinggan Ling under climate warming}

CHANG Yong-Xing, CHEN Zhen-Ju*, ZHANG Xian-Liang, BAI Xue-Ping, ZHAO Xue-Peng, LI Jun-Xia, and LU Xu Tree-ring Laboratory, College of Forestry, Shenyang Agricultural University, Shenyang 110866, China; and Research Station of Liaohe-River Plain Forest Ecosystem, Chinese Forest Ecosystem Research Network, Changtu, Liaoning 112500, China

\section{Abstract}

Aims The Da Hinggan Ling is amongst the areas in China susceptible to climate warming. The objective of this study is to determine the responses of radial growth to temperature variations in Larix gmelinii growing in different parts of the Da Hinggan Ling in the process of climate warming, by using dendrochronological techniques.

Methods We collected tree-ring samples from the southern, the middle and the northern parts of the main Da Hinggan Ling, developed site-specific ring-width chronologies, and synthesized tree-ring indices of the southern, the middle and the northern parts of the study area according to the first principal component loading factors for each chronology. The relationships between radial growth in L. gmelinii and temperature variations were determined with correlation analysis, and the differences in the responses of radial growth to temperature variations among various parts were analyzed and compared with principle component analysis.

Important findings There were notable discrepancies in the effects of temperature variations on radial growth in L. gmelinii between the southern and the northern parts of the study area (the middle part $>$ the northern part $>$ the southern part). In the southern part, the mean monthly temperature between the previous November and April of the current year had a significant relationship with tree-ring indices $(p<0.05)$. In the middle part, the mean monthly temperature during March and October of the current year had a significant relationship with tree-ring indices $(p<0.05)$, and so did the mean monthly temperature during June and August of the previous year $(p<$ 0.05). The mean monthly temperature during April and May of the current year had a highly significant relationship with tree-ring indices in the northern part $(p<0.01)$. This study suggests that the warmer and drier regional climate condition caused by elevated temperature has resulted in that soil moisture becomes the main factor limiting the radial growth, and the relationship between tree growth and temperature variations signified with aggravated

收稿日期Received: 2016-07-04 接受日期Accepted: 2017-01-03

* 通信作者Author for correspondence (E-mail: zhenjuchen@hotmail.com) 
soil drought under climate warming. The productivity in L. gmelinii as reflected by basal area increment experienced a shift response from cold stress to water stress. In addition, the radial growth in L. gmelinii in the Da Hinggan Ling will likely to show a declining trend in the southern and the middle parts, and an increasing trend in the northern part, in response to rapid warming in the coming decades.

Key words climate warming; the Da Hinggan Ling; Larix gmelinii; tree-ring width; radial growth; temperature variation; sensitivity

Citation: Chang YX, Chen ZJ, Zhang XL, Bai XP, Zhao XP, Li JX, Lu X (2017). Responses of radial growth to temperature in Larix gmelinii of the Da Hinggan Ling under climate warming. Chinese Journal of Plant Ecology, 41, 279-289. doi: 10.17521/cjpe.2016.0222

全球气温在20世纪20年代中期和70年代末期 经历了两次增温突变, 而第二次突变之后的几十年 是近百年来最暖的时期(王绍武和叶瑾琳，1995; IPCC, 2013), 由此引发的极端气候事件发生频率、 发生强度和发生范围也在增加, 而持续的高温将对 自然生态系统, 尤其是对森林生态系统造成极大的 负面影响(Alverson et al., 2000)。因此, 关于气候变 暖对森林生态系统的影响已成为目前的研究热点。

落叶松(Larix gmelinii)主要分布于我国全球变 化的敏感区域(李峰等, 2006)一一大兴安岭林区。长 期发育形成的落叶松林生态系统是大兴安岭地区代 表性较强的森林生态系统。落叶松作为高纬度地区 的优势树种, 具有寿命长、适应能力强的特点, 因其 年轮界限明显且径向生长对气候变化敏感的特性, 而被证明是用于树木年代学分析的理想树种(吴祥 定, 1990)。

目前, 开展关于大兴安岭地区落叶松径向生长 响应气候变暖方面的研究很有必要。首先, 有研究 发现, 在北半球高纬度地区, 随着全球温度升高, 树木生长对温度的敏感度降低(Jacoby \& D’Arrigo, 1995; Briffa et al., 2010), 然而也有研究发现, 随着 全球温度升高, 树木生长对温度的敏感度升高 (Andreu et al., 2007), 预示了气候变暖对树木生长 的显著影响; 其次, 我国关于大兴安岭地区落叶松 径向生长与温度变化关系的研究取得了重要进展, 如落叶松树轮宽度与树轮密度对气候变化响应关系 的对比(王丽丽等, 2005)、不同树龄落叶松年轮宽度 变化对气候变化的响应差异(Wang et al., 2009)和利 用落叶松树轮宽度指数重建夏季温度变化(Chen et al., 2013), 然而对气候变暖后相同生境的落叶松 生长特性和模式的南北差异研究很少; 最后, 关于 落叶松相关种属的生长与气候变化关系的研究多集 中于与我国临近的西伯利亚地区 (Andreu et al., 2007; Kujansuu et al., 2007; Sano et al., 2009; Wu et al., 2012; Bryukhanova et al., 2013)。为此, 本文采 集了大兴安岭地区落叶松年轮宽度数据, 并应用树 木年轮学方法探讨了落叶松响应气候变暖的生长模 式和发展趋势, 以期为大兴安岭林区森林生态系统 的管理和维护提供理论依据, 并为预测全球变化背 景下北半球高纬度地区树木生长提供数据基础。

\section{1 材料和方法}

\section{1 研究区概况}

研究区位于大兴安岭地区(图1), 地处欧亚大陆 中高纬度地带, 分跨黑龙江和内蒙古两省区, 属寒

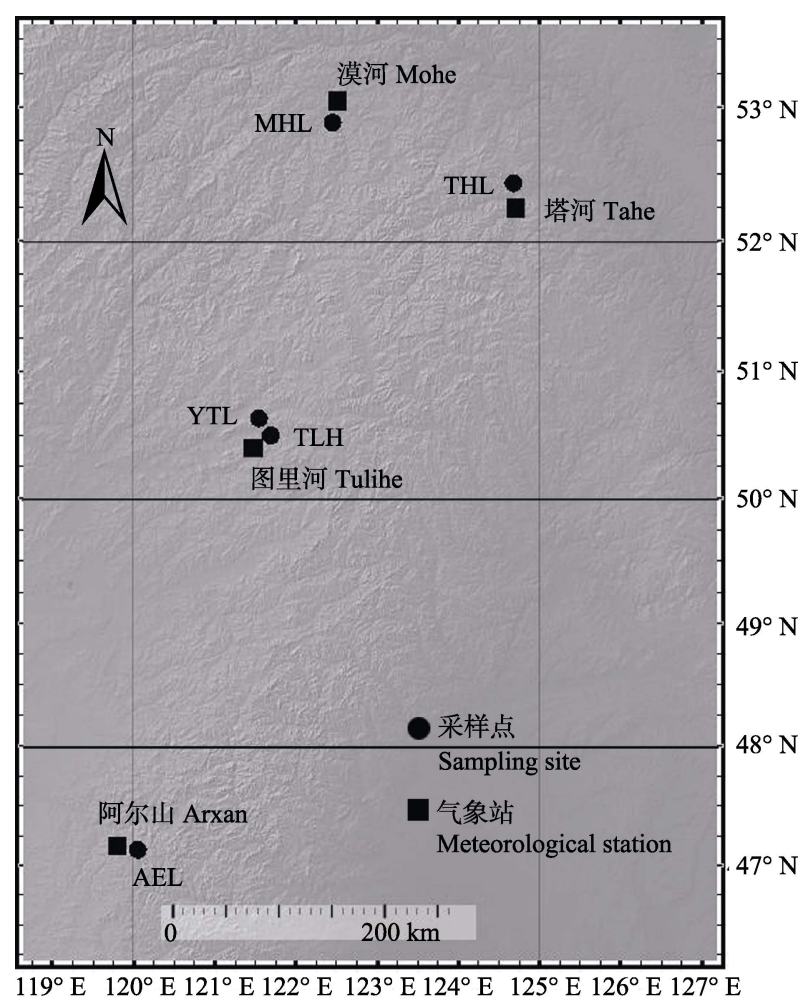

图1 研究区气象站和采样点分布位置。AEL, 阿尔山采样 点; MHL, 漠河采样点; THL, 塔河采样点; TLH, 图里河采 样点; YTL, 伊图里河采样点。

Fig. 1 Locations of sampling sites and meteorological stations in the study area. AEL, sampling site of Arxan; MHL, sampling site of Mohe; THL, sampling site of Tahe; TLH, sampling site of Tulihe; YTL, sampling site of Yitulihe. 
温带大陆性季风气候。域内多冻土和寒区环境分布, 山地主脉狭长且由高到低呈西南至东北走向, 地势 复杂，导致气候条件具有局地差异性(朱波，2000; 刘艳玲和朱天伟, 2009; 李喜恩, 2012): 阿尔山一带 的主脉南麓, 年降水量 $369.6 \mathrm{~mm}$, 年平均气温 $-2.5{ }^{\circ} \mathrm{C}$; 根河、图里河一带的主脉中段年降水量为 $443.1 \mathrm{~mm}$, 年平均气温 $-5.3{ }^{\circ} \mathrm{C}$; 塔河、漠河一带的主脉北段年 降水量为 $461.8 \mathrm{~mm}$, 年平均气温为 $-5.6{ }^{\circ} \mathrm{C}$ 。研究区 最暖月为7月 $\left(16.0-17.9{ }^{\circ} \mathrm{C}\right)$, 最冷月为 1 月 $(-25.4-$ $\left.-30.0{ }^{\circ} \mathrm{C}\right)$ 和12月 $\left(-22.1--28.4{ }^{\circ} \mathrm{C}\right)$, 降水集中在6-8 月, 占全年总和的 $65.9 \%-68.9 \%$ (图2)。近年来, 研 究区暖干化趋势明显。

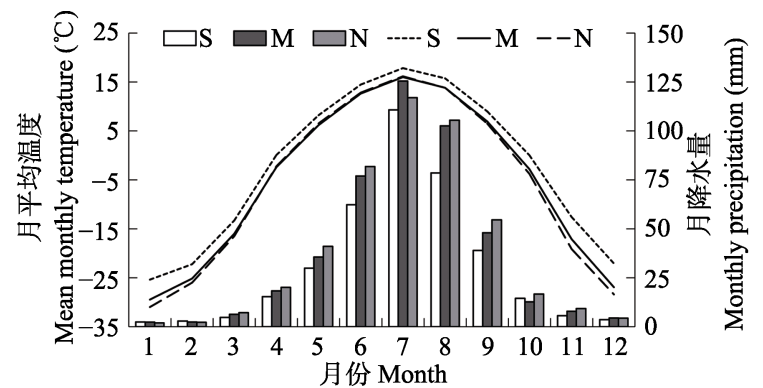

图2 研究区月平均温度(曲线)和月降水量(柱形)。 $M$, 大兴 安岭主脉中段; $N$, 大兴安岭主脉北段; S, 大兴安岭主脉南段。

Fig. 2 Monthly mean temperature (curves) and monthly precipitation (bars) in the study area. $\mathrm{M}$, middle section of the Da Hinggan Ling; N, northern section of the Da Hinggan Ling; S, southern section of the Da Hinggan Ling.

大兴安岭林区属欧亚针叶林区, 是欧亚针叶林 沿山地向南的延伸, 地带性植被是以落叶松为主体 的明亮针叶林, 在一定地域上掺杂着草甸、草原草 甸、草本沼泽等植被, 植被多集中于寒温带山地和 主脉两侧。与落叶松混生的其他树种有樟子松 (Pinus sylvestris var. mongolica)、蒙古栋(Quercus mongolica)、白桦(Betula platyphylla)、山杨(Populus davidiana)等。

\section{2 样本采集和年表建立}

采样点在大兴安岭主脉自西南到东北走向的 阿尔山(AEL)、图里河(TLH)、伊图里河(YTL)、塔 河(THL)和漠河(MHL)境内(图1), 为避免人为干扰 及其他非气候因素对树木生长的影响, 在原始林, 用口径 $5 \mathrm{~mm}$ 的生长锥在树木的胸径处钻取树芯样 本, 每树1-3芯, 共取阴坡的184株落叶松的352个样 芯。把样芯带回干燥处理并采用粗细不同的砂纸逐 级打磨至能在显微镜下清晰辨认为止, 然后进行交 叉定年(Fritts, 1976; 吴祥定, 1990), 并用精度为 $0.001 \mathrm{~mm}$ 的LINTAB5年轮宽度测量仪(RINNTECH, Heidelberg, German)测量年轮宽度, 采用COFECHA 程序(Holmes，1983) 检验交叉定年的结果。

树轮宽度不仅受环境和生态因子影响, 还受其 自身生理因子的控制, 故需在应用前去除树木自身 的生长趋势(方克艳等, 2015)。本研究以ARSTAN程 序(Cook, 1985; Cook \& Kairiukstis, 1990)为基础的 Signal-Free程序(Melvin \& Briffa, 2008)中提供的 Friedman函数拟合树木生长趋势, 并消除非气候因 素和树木生长趋势的影响, 得到标准化年表(StdCrn)、 Sig-Free年表(SsfCrn)、稳定后的标准化年表(StdStb)、 稳定后的Sig-Free年表(SsfStb) 4 个年轮宽度序列, 最终以含最多低频信号的Sig-Free年表(SsfCrn)为主 进行分析。

取1901-2010年为各年表的有效公共区间：各 点年表样本总体代表性(EPS)在1901-2010年均大于 0.85 (EPS大于 0.85 为年表的有效区间(Briffa et al., 2010))。年表的其他统计量如平均敏感度(MS)和信 噪比(SNR)等均达到了统计要求, 适宜年轮生态学 研究(表1): 平均敏感度(MS)越大则树木对气候变 化越敏感(Fritts, 1976; Cook \& Kairiukstis, 1990), 通 常在0.15-0.80之间的年表较优; 标准偏差反映年表

Table 1 Statistical characteristics in the Larix gmelinii chronologies

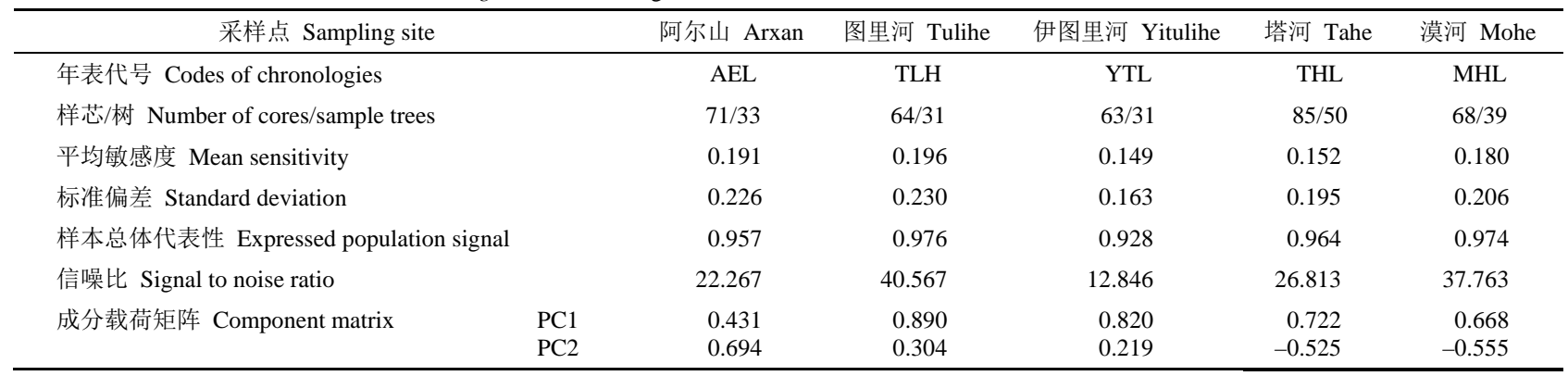

PC1, 第一主成分; PC2, 第二主成分。

PC1, the first principal component; PC2, the second principal component. 
的上下波动, 一般标准偏差越大, 年表所包含的气 候信息越多, 则对气候越敏感; 信噪比(SNR)是年表 承载气候信息量的指标(Cook \& Kairiukstis, 1990), 大于 4 的年表较优。

对各点年表序列(1901-2010年)进行主成分分 析, 根据主成分载荷矩阵发现, 与地理分布相对应, 大兴安岭主脉南段的阿尔山、中段的图里河与伊图 里河、北段的漠河与塔河的年轮指数的载荷量(主成 分与对应变量的相关系数)差别较大, 而主脉中段 和北段各自包含的年轮宽度序列对应的载荷量接近 (表1), 且在公共区间内各年轮序列极显著相关: 图 里河与伊图里河的相关系数 $r=0.812(p<0.01)$, 漠 河与塔河的相关系数 $r=0.645(p<0.01)$ 。因此, 可 对图里河与伊图里河、漠河与塔河的年轮宽度指数 取平均值合成大兴安岭主脉中段、北段的年轮宽度 序列, 阿尔山地区的年轮指数和这两个合成后的平 均值为 1 、最小值为 0 的无量纲序列在下文以南部、 中部、北部年轮宽度指数代表。

\section{3 气象数据}

气象数据来自于中国气象数据共享网(http:// data.cma.cn)。选取临近采样点的气象站(阿尔山、图 里河、漠河、塔河)的月值数据(平均温度、平均最 低温度、平均最高温度、月降水量、月相对湿度)。 其中, 北部的漠河、塔河气象站虽有一定距离, 但气 候资料具有很高的同质性, 例如, 月平均温度和月降 水量在公共区间内(1972-2013年)极显著相关(前者 $r=0.793-0.985$, 后者 $r=0.421-0.754, p<0.01)$, 因 此, 可对这两个气象站数据取平均值来消除随机误差。

1901-2014年区域格点温度 $\left(T_{r}\right)$ 采用荷兰皇家气 象研究所数据共享网站(http: //climexp.knmi.nl)分辨 率为 $0.5^{\circ} \times 0.5^{\circ}$ 的CRU TS3.23格点数据, 冻土资料 (1901-2001 年) 选用 NSIDC 数据集 $\left(47^{\circ}-48^{\circ} \mathrm{N}\right.$, $120^{\circ}-121^{\circ} \mathrm{E} ; 50^{\circ}-51^{\circ} \mathrm{N}, 121^{\circ}-122^{\circ} \mathrm{E} ; 52^{\circ}-53^{\circ} \mathrm{N}$, $122^{\circ}-125^{\circ} \mathrm{E}$ ), 归一化植被指数选用UMD GIMMS NDVI (1981-2006年)格点数据。格点温度变化在公 共区间(1959-2013年)与上述气象站数据具有很高 的同质性 $(r=0.858-0.970, p<0.01)$, 说明格点温度 具有区域代表性, 可弥补气象站数据时间序列短的 缺点。帕尔默干湿指数(PDSI, 1901-2012年)分辨率 为 $0.5^{\circ} \times 0.5^{\circ}$ 。区域格点温度、PDSI和 NDVI选用区 间均为 $47^{\circ}-53^{\circ} \mathrm{N} 、 119^{\circ}-125^{\circ} \mathrm{E}$ 。

本文所采用的气象站温度和区域格点温度均
为近地气温。

\section{4 数据处理}

Mann-Kendall方法检验温度的突变点。

采用伊万诺夫干湿指数 (K值) 描述区域干湿状 况，本文中 $K$ 值定义为:

$$
K=\frac{P}{0.0018(100-H)(25-T)^{2}}
$$

式中, $P 、 H 、 T$ 分别表示同期年降水量、年相对湿度、 年平均气温。 $K<0.13 、 0.13<K<0.3 、 0.3<K<0.6$ 、 $0.6<K<1.0$ 和 $K>1.0$ 分别代表极干旱、干旱、半干 旱、半湿润和湿润。

用冻结指数( $F$ 值)(Nelson \& Anisimov, 1997)描 述冻土动态, 本文中 $F$ 值计算公式如下:

$$
F=\frac{\sqrt{F D}}{\sqrt{T D}+\sqrt{F D}}
$$

式中, FD、TD分别表示同期冻土溶解深度和冻土冻 结深度。其中, $F<0.5 、 0.5<F<0.6$ 和 $F>0.6$ 分别 代表无多年冻土、不连续多年冻土和连续多年冻土。

采用胸高断面积增量 $(B A I)$ 描述落叶松的生长 变化, 本文中 $B A I$ 由以下公式得到:

$$
B A I=0.25\left[D B H^{2}+(D B H-2 a)^{2}\right]
$$

式中, $D B H 、 a$ 分别代表胸高 $1.3 \mathrm{~m}$ 处的断面积和同期 RAW年表指数(ARSTAN程序运行出的未标准化的 原始测量年表)。

上述指标的变化趋势除 $K$ 值(11年)外, 均采用 31 年滑动趋势系数指示(负值表示趋势下降)。

相关分析选取的气候资料为上一年6月到当年 10 月的平均气温、平均最高气温和平均最低气温, 采用1960-2010年的气象站数据。根据气象数据和植 被指数 $(N D V I)$ 的年内变化得出: 11-3月为冬季、4-5 月为树木生长季前、6-8月为树木生长季、9-10月为 秋季。利用季节性气象指标分析区域树木年轮的季 节性气候响应变化。上年生长季(PG)在上年6-8月; 上年秋季 $(\mathrm{PA})$ 在上年 $9-10$ 月; 上个冬季 $(\mathrm{PW})$ 在上年 11 月到当年 3 月; 生长季前(BG)在当年4-5月; 生长 季(CG)在当年6-8月。采用Dendroclim2002 (Biondi \& Waikul, 2004)的Evolutionary and Moving Response and Correlation模块分析敏感度随时间的变化, 滑动步长为 31 年, 用响应函数模块统计年轮宽度指 数对温度的敏感性(采用1901-2010年的区域格点温 度, 以敏感度绝对值界定树木生长对温度的响应程 度)。以线性回归模型模拟落叶松径向生长, 即以相 
关分析中篎选出的各地区落叶松径向生长的主要气 候限制因子所对应的气象站温度为自变量, 以年表 所对应的年轮宽度指数为因变量, 模拟落叶松实际 生长并预测未来气候变暖背景下树木的生长趋势。 为了得到最优方程, 采用逐步回归法对纳入方程的 自变量进行篮选, 且模型的调整决定系数(调整自由 度后的决定系数)充分考虑了样本数和自变量数。

主成分分析以主成分方差累计贡献率达到 $85 \%$ 以上和特征根大于 1 为依据, 确定主成分个数, 并以 主成分分析法(PCA)提取公因子。由于各变量均为 标准化后的年表, 在输入相关系数矩阵前不对原始 数据进行标准化。输出结果为主成分、主成分载荷 矩阵和因子得分系数矩阵。主成分分析由SPSS软件
完成。

\section{2 结果和分析}

\section{1 升温特征及其对落叶松生长的影响}

近百年来, 研究区在冬季和生长季前升温最明 显, 冬季升温速率为 $0.026{ }^{\circ} \mathrm{C} \cdot \mathrm{a}^{-1}$, 生长季升温速率 为 $0.021{ }^{\circ} \mathrm{C} \cdot \mathrm{a}^{-1}(p<0.01)$ 。 Mann-Kendall检验结果表 明：1960-2010年各区气象站年平均温度突变年份 分别为1988年、1982年、1976年; 区域格点温度在 1901-1980年间的突变年份为1925年，说明近百年 来研究区温度变化有两个明显的分界点：20世纪 20-30年代和70-80年代。1924-1954年和1984-2014 年分别是研究区近百年前、后段的最暖时期(图3A), 平均温度分别为 $-2.9{ }^{\circ} \mathrm{C}$ 和 $-1.9{ }^{\circ} \mathrm{C}$, 高于前、后半段
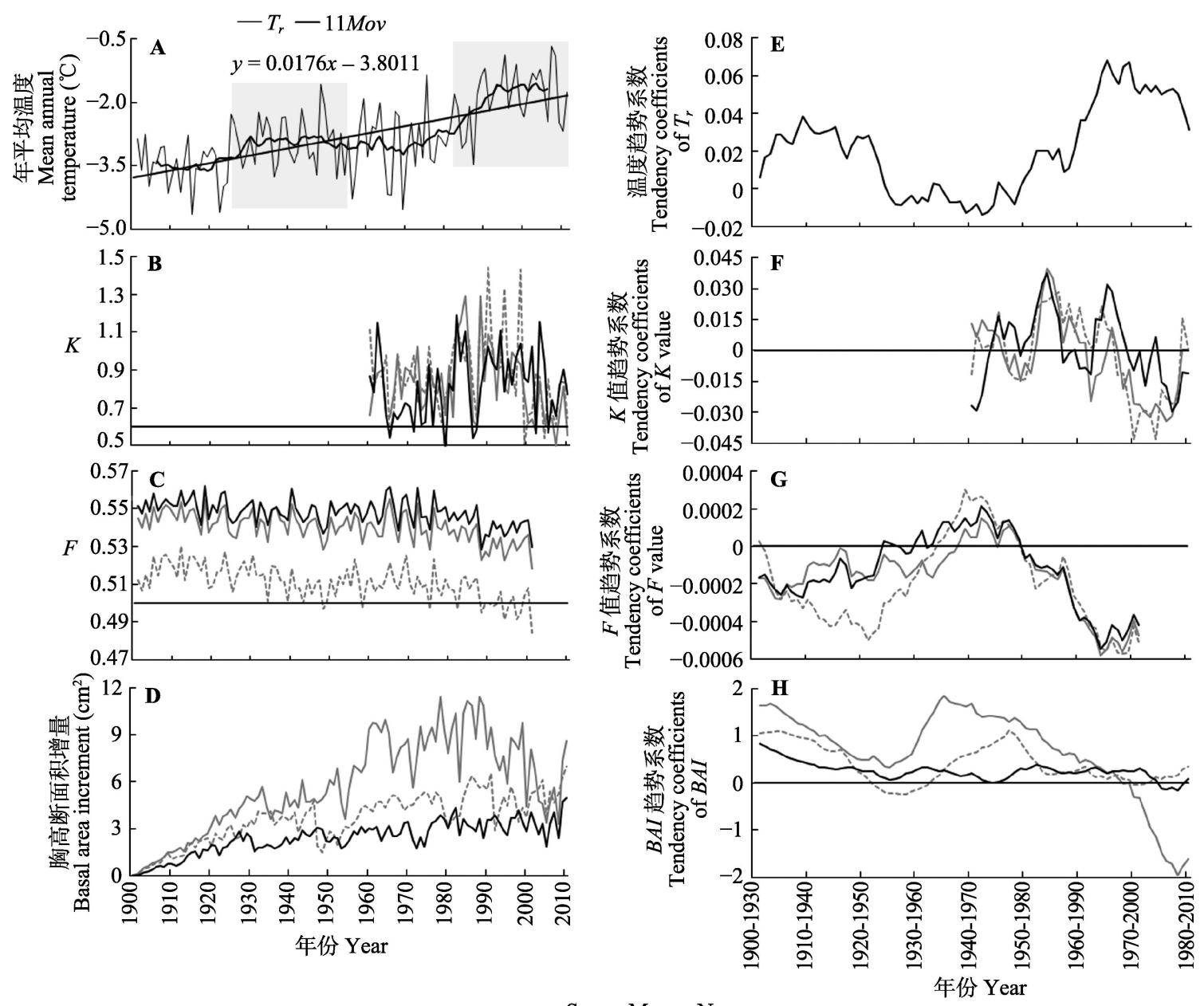

图3 区域平均温度 $\left(T_{r}\right)$ 、伊万诺夫干湿指数 $(K$ 值)、冻结指数 $(F$ 值)、胸高断面积增量 $(B A I)$ 的变化及其 31 年滑动趋势系数。 $\mathbf{A}$, 区域平均温度及其11年滑动平均值 $(11 \mathrm{Mov})$ 。 $\mathbf{B}, K$ 值。 C, $F$ 值。 D, 落叶松胸高断面积增量。 E、F、G、 H分别为 $T_{r} 、 K$ 值、F 值、BAI的趋势变化。 $\mathrm{M}$, 大兴安岭主脉中段; $\mathrm{N}$, 大兴安岭主脉北段; $\mathrm{S}$, 大兴安岭主脉南段。

Fig. 3 Changes in the regional mean temperature $\left(T_{r}\right)$, Mr Ivanov dry wet index ( $K$ value), freezing index $(F$ value), the basal area increment $(B A I)$ and their 31-year moving trend coefficients. A, Regional mean temperature and its 11-year moving mean (11 Mov). B, $K$ value of various parts. C, $F$ value of various parts. D, The basal area increment in Larix gmelinii in various parts. E, F, G and $\mathbf{H}$ presented the tendency coefficient of $T_{r}, K$ value, $F$ value and BAI. M, middle section of the Da Hinggan Ling; N, northern section of the Da Hinggan Ling; S, southern section of the Da Hinggan Ling. 
平均温度的 $8.7 \%$ 和 $24.3 \%$, 说明增温突变后研究区 进入了显著的升温期; 温度的趋势系数显示在19251955年至1949-1979年有一段低温阶段(图3E)。

$K$ 值指示的区域气候特征在1984年后呈下降趋 势, 该区域由半湿润转为半干旱(图3B、3F), 尤其中 部地区暖干化趋势最明显。冻土退化与升温过程相 对应(图3E、3G), 1901-2001年研究区冻土均为不连 续多年冻土, 其中南部地区在1988年后无多年冻土 分布(图3C)。胸高断面积增量 $(B A I)$ 指示的树木生长 量同期呈中部 $>$ 南部 $>$ 北部的趋势(图3D), 升温过程 中, 南部、中部落叶松 $B A I$ 呈下降趋势, 其中, 中部 地区落叶松的BAI在第二次升温过程中下降最显著 (图3H)。

\section{2 落叶松生长与温度变化的关系}

南部与中部落叶松年轮宽度指数极显著相关 $(r=$
0.379, $p<0.01)$, 中部与北部落叶松年轮宽度指数 极显著相关 $(r=0.445, p<0.01)$; 由于空间距离较远, 南部年轮指数和北部年轮指数不显著相关 $(r=0.055$, $p>0.05)$ 。落叶松径向生长对温度变化表现出明显 的响应差异, 其中, 南部、中部落叶松年轮指数与各 月、各季节温度变化多呈负相关关系, 而北部落叶 松年轮指数与各月、各季节温度变化多呈正相关关 系(图4)。南部落叶松生长对温度变化不敏感, 但7 月和上年冬季温度与其年轮指数有较高的负相关 (图4A)。中部落叶松年轮宽度与上年6-8月(上年生长 季, PG)温度显著相关(图4B, $p<0.05$ ), 其中6月的平 均温度和平均最高温度达到极显著水平 $(p<0.01)$; 中部年轮宽度还与当年3月、9月和10月的平均温度 显著负相关(图4B, $p<0.05$ )。北部落叶松年轮宽度 与当年 $4 、 5$ 月的温度显著正相关(图4C, $p<0.05$ ), 其

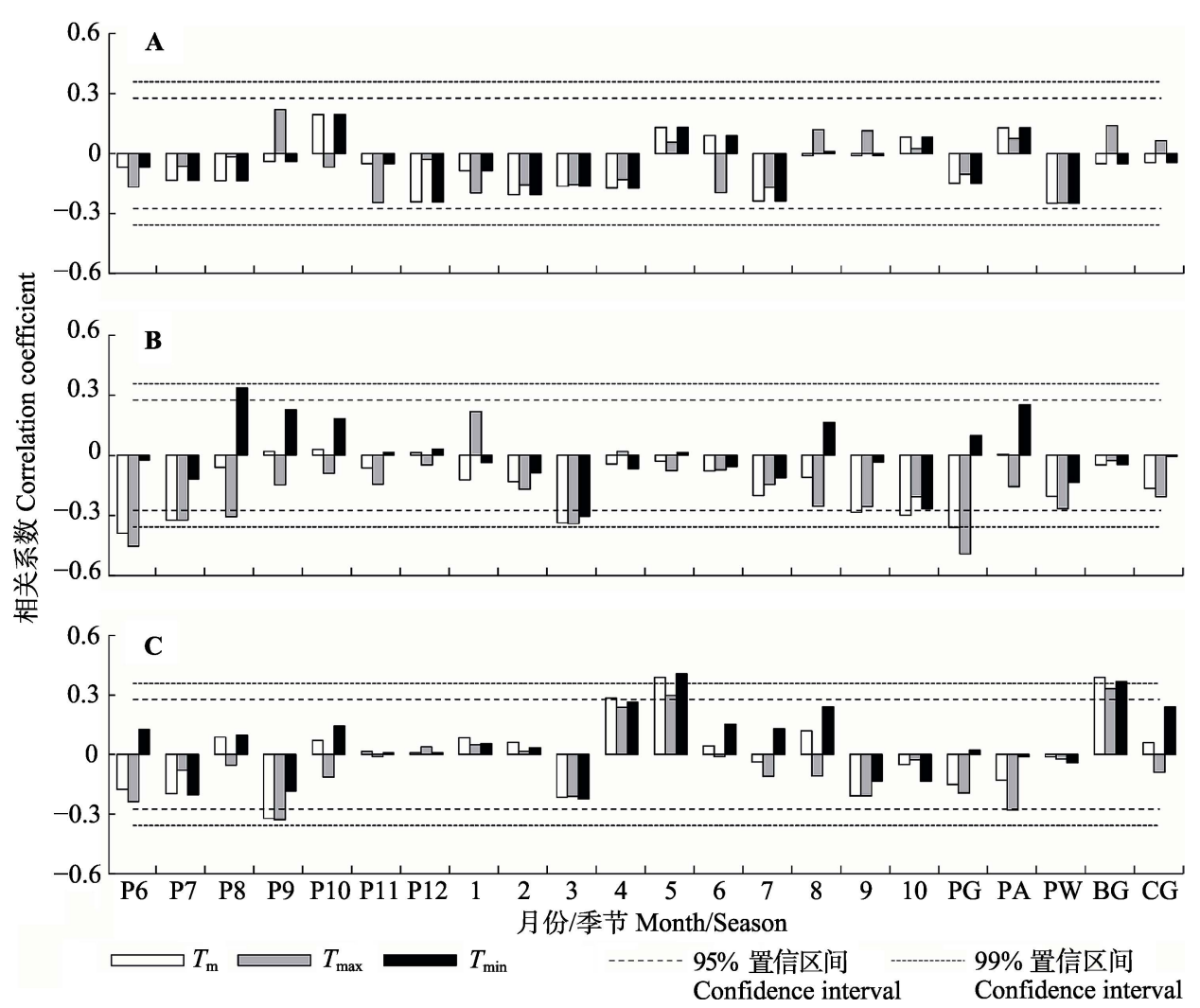

图4 落叶松年轮宽度指数与温度的相关关系。A, 大兴安岭南部落叶松年轮宽度指数与温度的相关系数。 $\mathrm{B}$, 大兴安岭中部 落叶松年轮宽度指数与温度的相关系数。 $\mathrm{C}$, 大兴安岭北部落叶松年轮宽度指数与温度的相关系数。 P6, 前一年的6月; P7, 前一年的7月; $\mathrm{P} 8$, 前一年的8月; $\mathrm{P} 9$, 前一年的9月; $\mathrm{P} 10$, 前一年的10月; P11, 前一年的11月; P12, 前一年的12月; BG, 生长季前; $\mathrm{CG}$, 当年生长季; $\mathrm{PA}$, 上年秋季; $\mathrm{PG}$, 上年生长季; $\mathrm{PW}$, 上年冬季; $T_{\mathrm{m}}$, 月/季度平均温度; $T_{\max }$, 月/季度平均最 高温度; $T_{\min }$, 月/季度平均最低温度。

Fig. 4 Correlations between tree-ring width index in Larix gmelinii and temperature. A, Correlation coefficients between tree-ring width index and temperature in the southern section of the Da Hinggan Ling. B, Correlation coefficients between tree-ring width index and temperature in the middle section of the Da Hinggan Ling. C, Correlation coefficients between tree-ring width index and temperature in the northern section of the Da Hinggan Ling. P6, last June; P7, last July; P8, last August; P9, last September; P10, last October; P11, last November; P12, last December; BG, pre-growth season; CG, current growth season; PA, last autumn; PG, last growth season; PW, last winter. $T_{\mathrm{m}}$, mean temperature on a monthly and seasonal basis; $T_{\max }$, mean maximum temperature on a monthly and seasonal basis; $T_{\min }$, mean minimum temperature on a monthly and seasonal basis.

www.plant-ecology.com 
中5月的平均温度和平均最低温度达到极显著水平 $(p$ $<0.01)$ 。此外, 南部落叶松生长与上年11月至当年 4 月平均温度显著相关 $(r=-0.300, p<0.05)$, 中部落 叶松生长与当年3-10月的平均温度显著相关 $(r=$ $-0.335, p<0.05$ ), 北部落叶松生长与4-5月(生长季 前, BG)平均温度极显著相关 $(r=0.388, p<0.01)$, 表明月份组合的温度变化对落叶松径向生长的影响 更具有代表性。

落叶松生长与区域格点温度的相关性与上述 相关性分析的结果一致, 例如: 南部落叶松生长与 当年7月 $(r=-0.215, p<0.05)$ 区域格点平均温度显 著相关; 中部落叶松生长与上年6月 $(r=-0.360, p<$ $0.01) 、$ 上年7月 $(r=-0.204, p<0.05)$ 、上年生长季 $(\mathrm{PG}$, $r=-0.331, p<0.01)$ 和当年10月 $(r=-0.238, p<0.05)$ 的区域格点平均温度显著相关; 北部落叶松生长与 当年5月 $(r=0.242, p<0.01)$ 和生长季前(BG, $r=$ $0.199, p<0.05)$ 的区域格点平均温度显著相关。

对阿尔山、图里河、伊图里河、塔河、漠河各 年轮宽度指数(1960-2010年)主成分分析发现: 第1 主成分 $\left(R^{2}=53.1 \%\right)$ 与 $P D S I$ 极显著相关 $(r=0.333, p<$ 0.01 ), 其中阿尔山年轮宽度指数在第 1 主成分的得 分系数(偏离均值程度)远小于其他各点; 第2主成分 $\left(R^{2}=25.8 \%\right)$ 与区域年平均温度显著相关 $(r=-0.306$, $p<0.05)$, 且各点在第2主成分的得分系数差别很大 (阿尔山 $>$ 塔河、漠河 $>$ 图里河、伊图里河), 说明温 度对落叶松生长的限制作用为中部>北部>南部。

\section{3 落叶松生长对温度响应的时间动态分析}

落叶松径向生长对温度的响应增强: 南部落叶 松生长与上年 11 月至当年 4 月的平均温度在 1952-1982年之后呈负响应, 且敏感度呈先升后降 的趋势(图5A); 中部落叶松生长与当年3-10月的平 均温度在1968-1998年之后呈负响应, 敏感度升高 且在1975-2005年之后达到显著水平(图5B, $p<$ 0.05); 北部落叶松生长与当年4-5月(生长季前, BG) 平均温度在1951-1981年之后呈正响应, 敏感度呈 升高趋势(图5C)。

基于相关分析建立的落叶松径向生长模型显 示: 与南部落叶松年轮宽度显著相关 $(p<0.05)$ 的上 年11月至当年 4 月平均温度可总体上解释南部落叶 松实际生长的 $9 \%$, 调整后的解释量为7.3\% $(r=0.3$, $F=5.3, p<0.05$ ), 解释量随温度升高而发生变化, 1988年(突变年份)之后可解释 $11.6 \%$ 的落叶松生长
变化; 与中部落叶松年轮宽度显著相关 $(p<0.05)$ 的 当年秋季(9-10月)和上年生长季(6-8月)平均温度可

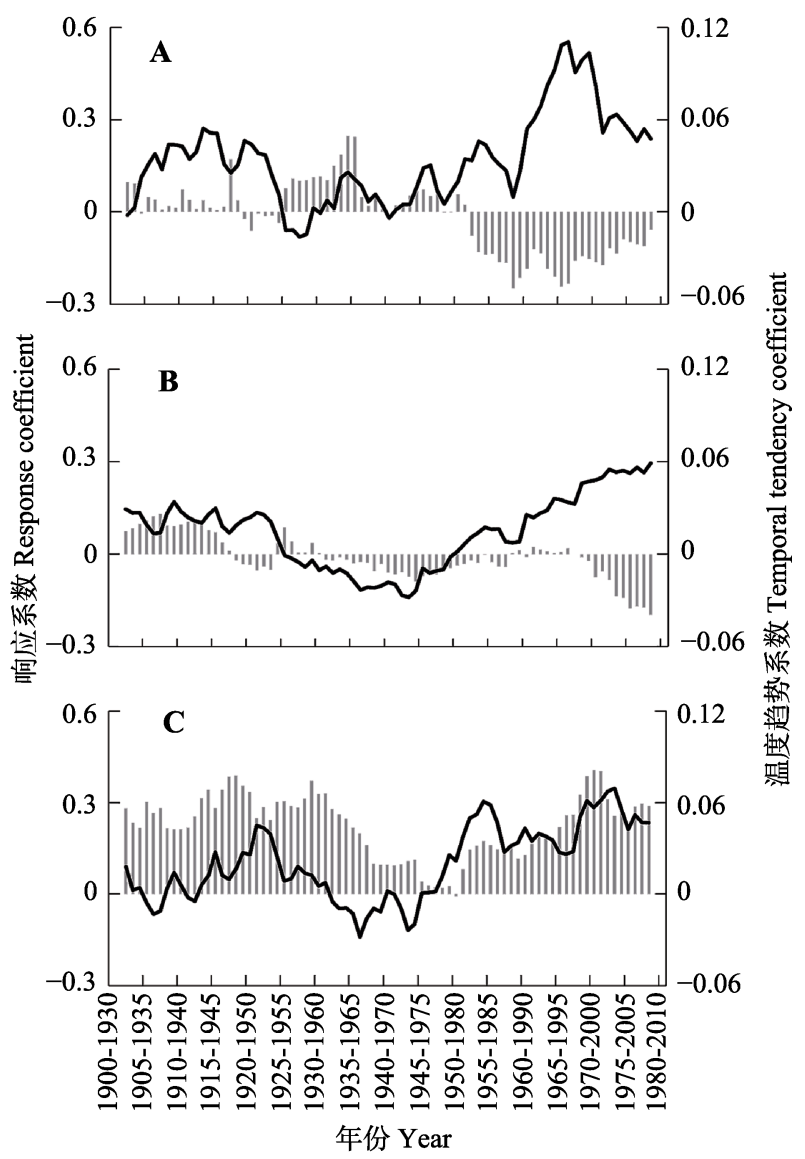

图5 落叶松年轮宽度指数对温度变化响应的稳定性。A, 大 兴安岭南部落叶松年轮宽度指数与 $11-4$ 月区域平均温度的 31年滑动响应系数和11-4月区域平均温度的趋势系数随时 间的变化。 $\mathbf{B}$, 大兴安岭中部落叶松年轮宽度指数与 $3-10$ 月 区域平均温度的 31 年滑动响应系数和3-10月区域平均温度 的趋势系数随时间的变化。C, 大兴安岭北部落叶松年轮宽 度指数与 $4-5$ 月区域平均温度的 31 年滑动响应系数和 $4-5$ 月 区域平均温度趋势系数随时间的变化。柱形为31年滑动响应 系数, 曲线为温度趋势系数。

Fig. 5 The climate response stabilities of tree-ring width index to temperature variations in Larix gmelinii. A, Temporal changes of 31-year moving response coefficient between tree-ring width index in L. gmelinii in the southern part of the Da Hinggan Ling and the regional mean temperature of November to April, together with the tendency coefficient of the regional mean temperature of November to April. B, Temporal changes of 31-year moving response coefficient between tree-ring width index in L. gmelinii in the middle part of the Da Hinggan Ling and the regional mean temperature of March to October, together with the tendency coefficient of the regional mean temperature of March to October. C, Temporal changes of 31-year moving response coefficient between tree-ring width index in L. gmelinii in the northern part of the Da Hinggan Ling and the regional mean temperature of April to May, together with the tendency coefficient of the regional mean temperature of April to May. Cylindrical bars represent the 31-year moving response coefficients, and the thick curves represented the thermal tendency coefficients. 
总体上解释中部落叶松实际生长的 $22.7 \%$, 调整后 的解释量为 $19.7 \%(r=0.477, F=7.361, p<0.01)$, 1982年(突变年份)之后可以解释 $56.4 \%$ 的落叶松生 长变化; 与北部落叶松年轮宽度极显著相关 $(p<$ 0.01)的当年5月平均温度可总体上解释北部落叶松 实际生长的 $13.9 \%$, 调整后的解释量为 $12.3 \%(r=$ $0.373, F=3.1, p<0.01$ ), 1976年(突变年份)后可以解 释16.5\%的落叶松生长变化。

\section{3 讨论}

\section{1 落叶松生长对温度的响应模式}

大兴安岭地势复杂, 气候条件具有局地差异性, 因而树木生长对温度变化的响应表现出明显的南北 差异。虽然单月温度变化对南部落叶松生长影响不 显著, 但月份组合的温度变化和区域耦合的水热条 件对该地区树木生长的影响更明显。例如, 上年11 月到当年 4 月平均温度和PDSI $\left(r_{P D S I}=-0.206, p<\right.$ 0.05)显著相关, 说明该地区树木生长还会间接地受 到水分条件的限制。秋季(尤其是10月)温度升高促 进休眠芽形成(袁玉江和李江风，1999)。9月树木生 长缓慢, 但树木的形成层并没有停止生理活动(张 先亮等, 2010; 李腾等, 2014), 因此秋季温度升高会 限制中部落叶松生长。临近地区的研究也发现了 3-9 月落叶松径向生长对温度变化的负响应, 此时温度 升高使蒸腾作用加剧, 树木根系得不到充足的水分, 因而不利于树木生长(张先亮等, 2010)。春季温度升 高加快了积雪融化速度, 使树木提前进入生长期 (Branning, 1999; 刘洪滨和邵雪梅, 2003)。5月温度 升高可加快树木萌芽, 有利于落叶松叶片增长 (Sano et al., 2009)。因此, 北部生长季前温度升高促 进了落叶松生长。临近地区的研究还发现, 5月最低 温度偏高, 春季回暖迅速(王丽丽等, 2005), 使落叶 松有充足的生长时间。

树木生长不仅受当年温度影响, 而且受上年温 度的调控, 这在生理学上称为“时滞效应” (吴祥定, 1990; 于大炮等, 2005)。树木生长一般与上年生长 季温度负相关(Branning, 1999)。例如, 6-8月是落叶 松的生长季, 树木生理活动频繁, 温度升高会使蒸 腾作用加剧, 为满足蒸腾作用所需, 树木会调动体 内储存的水分, 导致来年形成窄轮。

东北地区是我国受气候变暖影响最明显的地 区(王绍武等, 1998)。冬季升温趋势最明显, 且与落
叶松年轮指数负相关(图4), 说明冬季温度升高不利 于阴坡落叶松生长, 暖冬使降雪的频率和厚度减 少。而冬季雪盖可维持地温(戴竞波和李恩英, 1981; Kujansuu et al., 2007), 缓解树木受寒风和极端低温 的影响, 还能为树木来年生长提供水分(Chen et al., 2013)。

主成分分析结果显示: 落叶松年轮指数与区域 格点温度 $(p<0.05)$ 和PDSI $(p<0.01)$ 显著相关。由于 PDSI不仅能反映区域干旱程度和持续时间, 还能反 映地表的干旱状况(卫捷和马柱国, 2003), 因此, 落 叶松径向生长不仅受温度控制, 还可能受土壤水分 调控。大兴安岭地区是冻土分布区域(孙广友等, 2007; 吕久俊等, 2008), 所以落叶松生长与冻土环 境紧密相关: 冻土为其提供生长所需的水分, 而高 温使土壤冻结深度降低, 降低或消除了隔水层的保 护, 土壤保水性减弱, 进而在干旱的生长季不能为 落叶松生长提供充足的水分(Sugimoto et al., 2002)。 气候变暖还影响区域环境, 尤其自1984年以来区域 气候条件已呈从半湿润到半干旱转变的趋势(图3B、 $3 \mathrm{~F})$, 这种日益明显的气候暖干化也将是大兴安岭 湿地生态系统萎缩和退化的一个诱因(高永刚等, 2016)。因此, 高温引起的环境暖干化使土壤水分开 始成为限制落叶松径向生长的因素。

\section{2 气候变暖影响树木生长的水热驱动力}

落叶松径向生长主要受温度的限制, 表现为对 温度变化的差异性相关关系(图4)。一般来说, 树木 生长与温度负相关, 温度升高抑制树木生长, 反之 则促进树木生长(D’Arrigo et al., 2008)。落叶松径向 生长对温度的响应随着温度升高而增强(图5), 说明 气候变暖对树木生长的影响也日益增强: 南部、中 部地区落叶松生长与温度升高负相关, 说明温度升 高对树木生长不利, 北部地区落叶松生长与温度升 高正相关, 说明温度升高在一定程度上促进树木生 长。研究区在1919-1949年间温度平均年较差为 $46.31{ }^{\circ} \mathrm{C}$, 在1980-2010年大于 $5{ }^{\circ} \mathrm{C}$ 的年平均积温为 2 $102.8{ }^{\circ} \mathrm{C} \cdot \mathrm{d}\left(\right.$ 气温年较差为 $39.0-46.2{ }^{\circ} \mathrm{C}$ 、大于 $5{ }^{\circ} \mathrm{C}$ 积 温为 $1000-2100{ }^{\circ} \mathrm{C} \cdot \mathrm{d}$ 的地区适宜落叶松生长(杨志 香等, 2014)), 均已达到适宜落叶松生长的上限, 表 明在升温阶段研究区属于落叶松的非适宜生长区, 树木生长也经历了从响应低温到响应高温的过渡和 转化。自20世纪以来研究区内多为不连续多年冻土 分布, 在升温阶段, F值下降, 预示着加剧的冻土退 
化趋势(图3C)。通常情况下, 冻土部分消融后土壤 养分释放且树木根系活动空间增大, 但隔水层阻碍 了水分下渗, 使土壤水分沿冻结面向谷底流失(张 齐兵, 1994)。因此, 气候变暖是驱使落叶松生长量 下降的根本原因。

大兴安岭地区落叶松生长在高胁迫环境冻土 上, 在冻土发育地带, 落叶松生长受其影响而免于 外界干扰, 但长时间受冻土环境的高胁迫而生产力 偏低(张齐兵, 1994), 所以, 北部落叶松生长量低于 中、南部地区, 而其生长受限不显著(图3D、3H), 可 能是由于较厚的冻土避免了土壤养分过度流失, 使 树木生长的养分利用效率较高。在中、南部地区, 气 候变暖导致温度对落叶松径向生长具有抑制作用, 且在最近的增温突变年之后加剧(图5A、5B), 可能 是高温加剧了土壤水分流失引起的, 这与其他地区 的研究结果一致(Jacoby \& D’Arrigo, 1995; Lloyd \& Fastie, 2002; Oberhuber, 2004; Linares \& Tiscar, 2010; Wu et al., 2012)。中部地区临近半干旱区, 树木生长 受高温的抑制作用最明显, 因而落叶松生长量在近 几十年呈显著下降趋势。在气候变暖背景下, 西伯 利亚地区落叶松树木生产力经历了从响应低温胁迫 环境到响应水分胁迫环境的转变(Bryukhanova et al., 2013), 而近几十年的持续升温也驱使了大兴安岭 地区落叶松径向生长进行类似的响应转变。

\section{3 气候变暖对大兴安岭地区落叶松未来径向生 长的预测}

研究区增温突变发生在20世纪七八十年代, 与 全球气温的增温突变时间上一致(王绍武和叶瑾琳, 1995)。气候变暖导致的干旱程度加剧使树木生长对 温度变化的敏感度升高(图5), 因而落叶松径向生长 在增温突变年之后变化趋势明显。同时, 生长模型 模拟的落叶松径向生长趋势与树木实际生长趋势基 本一致, 模型解释量在突变年之后随环境变化而升 高, 也表明了气候变暖对树木生长的显著影响。本 研究发现, 南部和中部落叶松径向生长分别与上年 11月到当年 4 月和上年生长季、当年3-10月平均温度 显著负相关 $(p<0.05)$, 北部落叶松径向生长与生长 季前平均温度极显著正相关 $(p<0.01)$ 。因此, 若研 究区温度在未来几十年持续升高, 落叶松径向生长 量将呈南部和中部降低、北部升高的趋势。

基于RCM-PRECIS模型模拟的两种排放情景 下, 2015年至2050年间大兴安岭地区温度增量为
$0.054{ }^{\circ} \mathrm{C} \cdot \mathrm{a}^{-1}$ 和 $0.041{ }^{\circ} \mathrm{C} \cdot \mathrm{a}^{-1}$ (高永刚等, 2016), 假定各 月温度升高趋势相同, 模拟的南部落叶松径向生长 量每10年分别下降 $5.1 \%$ 和 $3.9 \%$, 中部落叶松径向生 长量每10年将分别下降8.3\%和6.3\%, 而北部落叶松 径向生长量每 10 年将分别上升 $6.9 \%$ 和 $5.3 \%$ 。未来气 候变暖背景下, 落叶松的适宜地理分布区将逐渐北 移(李峰等, 2006), 若升温趋势得不到有效缓解, 最 终可能破坏落叶松林生态系统平衡。落叶松林生态 系统受气候变化和生物因子的影响, 未来气候变化 情景具有不确定性, 所以模型模拟具有一定的局限 性。因此, 准确评估气候变暖对大兴安岭落叶松林 生态系统的影响, 有待于更全面的气候响应研究。

基金项目 国家自然科学基金(41271066、31570632、 41571094和41601045)。

致谢东北林业大学林学院的张錐同学在本文数据 处理方面给予的指导和帮助, 在此表达诚挚的谢意。

\section{参考文献}

Alverson KD, Oldfield F, Bradley RS (2000). Past global changes and their significance for the future. Journal of Quaternary Science, 15, 657-658.

Andreu L, Gutierrez E, Macias M, Ribas M, Bosch O, Camarero JJ (2007). Climate increases regional treegrowth variability in Iberian pine forests. Global Change Biology, 13, 807-815.

Biondi F, Waikul K (2004). Dendroclim2002: A C++ program for statistical calibration of climate signals in tree-ring chronologies. Computers and Geosciences, 30, 303-311.

Branning A (1999). Dendroclimatological potential of droughtsensitive tree stands in southern Tibet for the reconstruction of monsoonal activity. Lawa Journal, 20, 325-338.

Briffa KR, Schweingruber FH, Jones PD, Osborn TJ, Shiyatov SG, Vaganov EA (2010). Reduced sensitivity of recent tree-growth to temperature at high northern latitudes. $\mathrm{Na}$ ture, 391, 678-682.

Bryukhanova M, Fonti P, Kirdyanov A, Saurer M, Siegwolf R, Pochebit N, Sidorova O, Prokushkin A (2013). Growth of trees on permafrost: Habitat driven response to climate. EGU General Assembly, 15, 469-473.

Chen ZJ, Zhang XL, He XY, Davi NK, Cui MX, Peng JJ (2013). Extension of summer (Jun.-August) temperature records for northern Inner Mongolia (1715-2008), China using tree rings. Quaternary International, 283, 21-29.

Cook ER (1985). A Time Series Analysis Approach to Tree Ring Standardization. University of Arizona Press, Tucson, USA. 
Cook ER, Kairiukstis LA (1990). Methods of Dendrochronology: Applications in the Environment Sciences. Kluwer Academic Publishers, Boston, USA.

Dai JB, Li EY (1981). Influence of snow cover to the ground temperature in the permafrost region in the northern part of the Great Xinan Mountain. Journal of Glaciology and Geocryology, 3(1), 10-18. (in Chinese with English abstract) [戴竞波, 李恩英 (1981). 大兴安岭北部多年冻 土地区雪盖对地温的影响. 冰川冻土, 3(1), 10-18.]

D’Arrigo R, Wilson R, Liepert B, Cherubini P (2008). On the "divergence problem" in northern forests: A review of the tree-ring evidence and possible causes. Global and Planetary Change, 60, 289-305.

Fang KY, Yang B, Zheng HZ, Li YJ, Zhou FF, Dong ZP, Cao CF, Li DW, Chen YJ (2015). Applying tree-ring methods in the global changes studies. Quaternary Sciences, 35, 1283-1893. (in Chinese with English abstract) [方克艳, 杨保, 郑怀舟, 李颖俊, 周非飞, 董志鹏, 曹春福, 李大 稳, 陈亚君 (2015). 树轮学研究方法及其在全球变化中 的应用. 第四纪研究, 35, 1283-1893.]

Fritts HC (1976). Tree Rings and Climate. Academic Press, New York.

Gao YG, Zhao HY, Gao F, Zhu HX, Qu HH, Zhao F (2016). Climate change trend in future and its influence on wetlands in the Great Khingan Mountains. Journal of Glaciology and Geocryology, 38(1), 47-56. (in Chinese with English abstract) [高永刚, 赵慧颖, 高峰, 朱海霞, 曲辉 辉, 赵放 (2016). 大兴安岭区域未来气候变化趋势及其 对湿地的影响. 冰川冻土, 38(1), 47-56.]

Holmes RL (1983). Computer-assisted quality control in treering dating and measurement. Tree-Ring Bulletin, 43, 69-78.

IPCC (Intergovernmental Panel on Climate Change) (2013). Climate Change 2013: The Physical Science Basis. Cambridge University Press, Cambridge, UK.

Jacoby GC, D’Arrigo RD (1995). Tree ring width and density evidence of climatic and potential forest change in Alaska. Global Biogeochemical Cycles, 9, 227-234.

Kujansuu J, Yasue K, Koike T, Abaimov AP, Kajimoto M, Matsuura Y (2007). Climatic responses of tree-ring widths of Larix gmelinii on contrasting north-facing and south-facing slopes in central Siberia. Journal of Wood Science, 53, 87-93.

Li F, Zhou GS, Cao MC (2006). Responses of Larix gmelinii geographical distribution to future climate change: A simulation study. Chinese Journal of Applied Ecology, 17, 2255-2260. (in Chinese with English abstract) [李峰, 周 广胜, 曹铭昌 (2006). 兴安落叶松地理分布对气候变化 响应的模拟. 应用生态学报, 17, 2255-2260.]

Li T, He XY, Chen ZJ (2014). Tree growth responses of Mongolian oak (Quercus mongolica) to climate change in southern Northeast: A case study in Qianshan Mountains. Chinese Journal of Applied Ecology, 25, 1841-1848. (in
Chinese with English abstract) [李腾, 何兴元, 陈振举 (2014). 东北南部蒙古栎径向生长对气候变化的响应 -一以千山地区为例. 应用生态学报, 25, 1841-1848.]

Li XE (2012). The Chorography of Forestry Management Bureau of the Da Hinggan Range, Forest Industry Enterprise Group of Nei Mongol, China. Inner Mongolian Culture Press, Hulun Buir, Nei Mongol. (in Chinese) [李喜恩 (2012). 中国内蒙古森工集团内蒙古大兴安岭林管局志. 内蒙古文化出版社, 内蒙古呼伦贝尔.]

Linares JC, Tiscar PA (2010). Climate change impacts and vulnerability of the southern populations of Pinus nigra subsp. salzmannii. Tree Physiology, 30, 795-806.

Liu HB, Shao XM (2003). Reconstruction of early-spring temperature of Qinling Mountains using tree-ring chronologies. Acta Geographica Sinica, 58, 879-884. (in Chinese with English abstract) [刘洪滨, 邵雪梅 (2003). 利用树 轮重建秦岭地区历史时期初春温度变化. 地理学报, 58 , 879-884.]

Liu YL, Zhu TW (2009). The Chorography of Mohe County. Heilongjiang People's Publishing House, Harbin. (in Chinese) [刘艳玲, 朱天伟 (2009). 漠河县志. 黑龙江人民 出版社, 哈尔滨.]

Lloyd AH, Fastie CL (2002). Spacial and temporal variability in the growth and climate response of treeline trees in Alaska. Climate Change, 52, 481-509.

Lü JJ, Li XZ, Hu YM, Wang XW, Sun J (2008). Application of frost number model in northeast China permafrost regionalization. Chinese Journal of Applied Ecology, 19, 2271-2276. (in Chinese with English abstract) [吕久俊, 李秀珍, 胡远满, 王宪伟, 孙菊 (2008). 冻结数模型在 中国东北多年冻土分区中的应用. 应用生态学报, 19, 2271-2276.]

Melvin TM, Briffa KR (2008). A "signal-free” approach to dendroclimatic standardisation. Dendrochronologia, 26, 71-86.

Nelson FE, Anisimov OA (1997). Permafrost zonation and climate change in the northern hemisphere: Results from transient general circulation models. Climate Change, 35, 241-258.

Oberhuber W (2004). Influence of climate on radial growth of Pinus cembra within the alpine timberline ecotone. Tree Physiology, 24, 291-301.

Sano M, Furuta F, Sweda T (2009). Tree-ring-width chronology of Larix gemelinii as an indicator of changes in early summer temperature in east-central Kamchatka. Journal of Forest Research, 14, 147-154.

Sugimoto A, Yanagisawa N, Naito D, Fujita N, Maximov TC (2002). Importance of permafrost as a source of water for plants in east Siberian taiga. Ecological Research, 17, 493-503.

Sun GY, YU SP, Wang HX (2007). Causes, south borderline and surbareas of permafrost in Da Hinggan Mountains and

www.plant-ecology.com 
Xiao Hinggan Mountains. Acta Geographica Sinica, 27(1), 68-74. (in Chinese with English abstract) [孙广友, 于少 鹏, 王海霞 (2007). 大小兴安岭多年冻土的主导成因及 分布模式. 地理科学, 27(1), 68-74.]

Wang LL, Shao XM, Huang L, Liang EY (2005). Tree-ring characteristics of Larix gmelinii and Pinus sylvestris var. mongolica and their response to climate in Mohe, China. Acta Phytoecologica Sinica, 29, 380-385. (in Chinese with English abstract) [王丽丽, 邵雪梅, 黄磊, 梁尔源 (2005). 黑龙江漠河兴安落叶松与樟子松树轮生长特性 及其对气候的响应. 植物生态学报, 29, 380-385.]

Wang SW, Ye JL (1995). A analysis of global warming during the last one hundred years. Chinese Journal of Atmospheric Sciences, 19, 545-553. (in Chinese with English abstract) [王绍武, 叶瑾琳 (1995). 近百年全球气候变 暖的分析. 大气科学, 19, 545-553.]

Wang SW, Ye JL, Gong DY, Zhu JH, Yao CD (1998). Construction of mean annual temperature series for the last one hundred years in China. Quarterly Journal of Applied Meteorology, 9, 392-401. (in Chinese with English abstract) [王绍武, 叶瑾琳, 龚道溢, 朱锦红, 姚檀栋 (1998). 近百 年中国年气温序列的建立. 应用气象学报, 9, 392-401.]

Wang XC, Zhang YD, Mcrae DJ (2009). Spatial and agedependent tree-ring growth responses of Larix gmelinii to climate in northeastern China. Trees, 23, 875-885.

Wei J, Ma ZG (2003). Comparison of Palmer drought severity index, percentage of precipitation anomaly and surface humid index. Acta Geographica Sinica, 58, 117-124. (in Chinese with English abstract) [卫捷, 马柱国 (2003). Palmer干旱指数、地表湿润指数与降水距平的比较. 地 理学报, 58, 117-124.]

Wu XC, Liu HY, Guo DL, Anenkhonov OA, Badmeava NK, Sandanov DV (2012). Growth decline linked to warming-induced limitation in Hemi-Boreal forests. PLOS ONE, 7, e42619. doi: 10.1371/j.pone.0042619.

Wu XD (1990). Tree-Rings and Climate Change. China Meteorological Press, Beijing. (in Chinese) [吴祥定 (1990). 树木年轮与气候变化. 气象出版社, 北京.]

Yang ZX, Zhou GS, Yin XJ, Jia BR (2014). Geographic distri- bution of Larix gmelinii natural forest in China and its climatic suitability. Chinese Journal of Ecology, 33, 14291436. (in Chinese with English abstract) [杨志香, 周广胜, 殷晓洁, 贾丙瑞 (2014). 中国兴安落叶松天然林地理分 布及其气候适宜性. 生态学杂志, 33, 1429-1436.]

Yu DP, Wang SZ, Tang LN, Dai LM, Wang QL, Wang SX (2005). Relationship between tree-ring chronology of Larix olgensis in Changbai Mountains and the climate change. Chinese Journal of Applied Ecology, 16, 14-20. (in Chinese with English abstract) [于大炮, 王顺忠, 唐立 娜, 代力民, 王庆礼, 王绍先 (2005). 长白山北坡落叶 松年轮年表及其与气候变化的关系. 应用生态学报, 16 , 14-20.]

Yuan YJ, Li JF (1999). Reconstruction and analysis of 450 year's winter temperature series in Ürümqi River source of Tianshan Mountains. Journal of Glaciology and Geocryology, 21(1), 64-70. (in Chinese with English abstract) [袁 玉江, 李江风 (1999). 天山乌鲁木齐河源450 a冬季温 度序列的重建与分析. 冰川冻土, 21(1), 64-70.]

Zhang QB (1994). The responses of vegetation on northern part of Mt. Daxinganling to strongly enforced permafrost environment and environmental disturbances. Journal of Glaciology and Geocryology, 16(2), 97-103. (in Chinese with English abstract) [张齐兵 (1994). 大兴安岭北部植 被对高胁迫冻土环境及干扰的响应. 冰川冻土, 16(2), 97-103.]

Zhang XL, Zhang XL, Cui MX, Ma YJ, Wu T, Chen ZJ, Ding WH (2010). Larix gmelinii tree-ring width chronology and its response to climate change in Kuduer, Great Xing'an Mountains. Chinese Journal of Applied Ecology, 21, 2501-2507. (in Chinese with English abstract) [张先亮, 崔明星, 马艳军, 吴涛, 陈振举, 丁玮航 (2010). 大兴 安岭库都尔地区兴安落叶松年轮宽度年表及其与气候 变化的关系. 应用生态学报, 21, 2501-2507.]

Zhu B (2000). The Chorography of Tahe County. Zhonghua Book Company, Beijing. (in Chinese) [朱波 (2000). 塔河 县志. 中华书局, 北京.]

责任编委: 岳 明 责任编辑: 王 藏

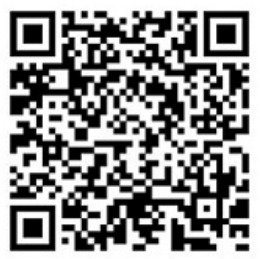

扫码向作者提问 